\title{
Epoetin Delta Reduces Oxidative Stress in Primary Human Renal Tubular Cells
}

\author{
Annelies De Beuf, ${ }^{1}$ Xiang-hua Hou, ${ }^{1,2}$ Patrick C. D'Haese, ${ }^{1}$ and Anja Verhulst ${ }^{1}$ \\ ${ }^{1}$ Laboratory of Pathophysiology, Faculties of Medicine and Biomedical, Pharmaceutical and Veterinary Sciences, University of Antwerp, \\ Universiteitsplein 1, 2610 Antwerp, Belgium \\ ${ }^{2}$ Department of Nephrology, The Second Hospital, Shandong University, Jinan 250033, China
}

Correspondence should be addressed to Patrick C. D’Haese, patrick.dhaese@ua.ac.be

Received 16 November 2009; Revised 17 February 2010; Accepted 17 February 2010

Academic Editor: Xudong Huang

Copyright (C) 2010 Annelies De Beuf et al. This is an open access article distributed under the Creative Commons Attribution License, which permits unrestricted use, distribution, and reproduction in any medium, provided the original work is properly cited.

Erythropoietin (EPO) exerts (renal) tissue protective effects. Since it is unclear whether this is a direct effect of EPO on the kidney or not, we investigated whether EPO is able to protect human renal tubular epithelial cells (hTECs) from oxidative stress and if so which pathways are involved. EPO (epoetin delta) could protect hTECs against oxidative stress by a dose-dependent inhibition of reactive oxygen species formation. This protective effect is possibly related to the membranous expression of the EPO receptor (EPOR) since our data point to the membranous EPOR expression as a prerequisite for this protective effect. Oxidative stress reduction went along with the upregulation of renoprotective genes. Whilst three of these, heme oxygenase-1 (HO-1), aquaporin1 (AQP-1), and B-cell CLL/lymphoma 2 (Bcl-2) have already been associated with EPO-induced renoprotection, this study for the first time suggests carboxypeptidase M (CPM), dipeptidyl peptidase IV (DPPIV), and cytoglobin (Cygb) to play a role in this process.

\section{Introduction}

Oxidative stress occurs when there is an imbalance between the generation of reactive oxygen species (ROS) and a biological system's ability to detoxify the reactive intermediates or repair the resulting damage [1], and is associated with processes such as infection, inflammation, and ischemia/reperfusion injury (IRI) [2]. To minimize ROSinduced damaging effects, aerobic organisms developed antioxidant defense mechanisms to counteract the oxidant effects. Besides endogenous molecules, the protective effect of various exogenous compounds against oxidative stress has also been investigated [3, 4]. Recombinant erythropoietin (EPO) is one of these exogenous compounds and has been found to possess antioxidant properties in addition to its original hematopoietic function [5].

Although it is known that EPO is able to attenuate (acute and chronic) kidney failure [6], it is not yet clear whether this is the result of a direct effect of EPO on renal (tubular) cells or of a systemically EPO-induced effect. Therefore, it was investigated in the present in vitro study whether the renoprotective effects of EPO can, at least to a certain extent, be explained by a direct, antioxidant effect of EPO on the renal (tubular) cells. More precisely the effect of EPO (epoetin delta, a recombinant EPO molecule produced in a human cell line through gene-activation technology) on glucose oxidase (GO)-induced oxidative stress in primary cultures of human renal tubular epithelial cells (hTECs) was evaluated.

As a next step, we investigated (i) whether the EPO receptor (EPOR) is involved herein, (ii) the contribution of genes previously linked to EPO-induced protective mechanisms, such as heme oxygenase-1 (HO-1), aquaporin1 (AQP-1), and B-cell CLL/lymphoma-2 (Bcl-2), and (iii) a possible role for carboxypeptidase M (CPM) dipeptidyl peptidase IV (DPPIV) and cytoglobin (Cygb) genes not yet linked to EPO-induced renoprotective mechanisms but to oxidative stress in general. 


\section{Material and Methods}

2.1. Culture of Primary Human Tubular Kidney Cells. Primary hTECs were isolated as previously described $[7,8]$. Briefly, normal human kidney tissue, that became available through nephrectomies performed on oncological indication, was collected and processed in a sterile manner. The use of this tissue for the purpose of cell culture was approved by the Local Ethical Committee. Macroscopically normal tissue was decapsulated. Tissue from cortex and outer stripe of outer medulla was dissected, cut into pieces of approximately $1 \mathrm{~mm}^{3}$, and digested in collagenase D solution. The suspension was shaken vigorously for 2 hours at $37^{\circ} \mathrm{C}$ and sieved through a $120 \mu \mathrm{m}$ sieve. The resulting single-cell suspension was loaded on top of a discontinuous Percoll gradient with densities of 1.04 and $1.07 \mathrm{~g} / \mathrm{mL}$. After centrifugation, tubular cells were carefully aspirated, washed, and brought into culture on 48 -well plates or glass coverslips in $\alpha$-minimal essential medium ( $\alpha$-MEM) modified according to GibsonD'Ambrosio [9] and supplemented with $10 \%$ of fetal calf serum. Fetal calf serum-containing medium was replaced by serum-free, Gibson-d'Ambrosio-modified $\alpha$-MEM medium 24 hours before performing the experiments.

2.2. Administration of Epoetin Delta and Epoetin Alfa. Confluent hTECs were incubated with different concentrations of epoetin delta (Dynepo, Shire Pharmaceuticals Ltd.; 0-5-100 IU/mL) or epoetin alfa (Eprex, Janssen-Cilag; $100 \mathrm{IU} / \mathrm{mL}$ ) for 24 hours before or concomitantly with the induction of oxidative stress (at least 4 wells per condition).

2.3. Induction of Oxidative Stress by GO. Oxidative stress was induced by exposure of confluent hTECs to different concentrations of GO (Sigma; 0-0.1-1-5-10-50-100 IU/mL) for different time periods ( 20 minutes, 30 minutes, 40 minutes, 1 hour, 2 hours, 3 hours, and 4 hours) [3,10].

2.4. Measurement of Oxidative Stress. The GO-induced oxidative stress, assessed as the amount of generated cellular radicals, was measured by the $2^{\prime}, 7^{\prime}$-dichlorodihydrofluorescein diacetate $\left(\mathrm{H}_{2} \mathrm{DCFDA}\right.$, Sigma) molecule. $\mathrm{H}_{2}$ DCFDA is metabolized to nonfluorescent DCFA by intracellular esterases and to fluorescent DCF by free oxygen radicals. DCF fluorescence was measured using fluorometry at excitation and emission wavelengths of $485 \mathrm{~nm}$ and $535 \mathrm{~nm}$, respectively.

2.5. RNA Isolation and Quantitative Real-Time RT-PCR. The mRNA expression of HO-1, AQP-1, Bcl-2, CPM, DPPIV, and Cygb in hTECs was analyzed by means of the quantitative real-time reverse transcription-polymerase chain reaction (real-time RT-PCR) using the fluorescent TaqMan methodology and the ABI Prism 7000 Sequence Detection System (Applied Biosystems). According to the manufacturer's instructions, cDNA was synthesized from total RNA extracted with the High Pure RNA Isolation Kit (Roche) using the High-Capacity cDNA Archive kit (Applied Biosystems). Ready to use, predesigned, primer and probe sets (Applied Biosystems)for human genes of inter- est (Hs00157965_m1 for HO-1, Hs00166067_m1 for AQP1, Hs00153350_m1 for Bcl-2, Hs00266395_m1 for CPM, Hs00175210_m1 for DPPIV, Hs00370478_m1 for Cygb) and the housekeeping gene GAPDH (Hs99999905_m1) were used according to the manufacturer's guidelines. The mRNA quantity of the investigated genes was analyzed in triplicate, normalized against GAPDH, and expressed in relation to a calibrator sample using the comparative Ct method. Control cell cultures, that is, cultures receiving neither GO nor epoetin delta served as the calibrator sample, which was given a gene of interest/GAPDH mRNA expression ratio of 1 .

2.6. Erythropoietin Receptor Immunofluorescence. Confluent hTECs were fixed in $4 \%$ formaldehyde for 10 minutes. Cells were incubated overnight with the M-20 anti-EPOR antibody (Santa Cruz Biotechnology) and subsequently with FITC-labeled goat anti-rabbit IgG antibody during 2 hours. Sections in which the primary antibody was omitted served as negative control.

2.7. Study Setup and Statistical Analysis. Because of the interindividual variation in DCF fluorescence and mRNA expression levels of some investigated genes in cell monolayers derived from individual kidney samples, some data are represented as single representative experiments. Data are presented as mean \pm SD. Statistics were performed with SPSS 16.0. Comparisons between the study groups for each time point and/or GO dose were assessed using a Kruskal-Wallis test, followed by a Mann-Witney $U$-test in combination with Bonferroni correction when more than two groups were compared. Statistical comparison of mean values of quantitative real-time RT-PCR analyses was performed with GraphPad Prism 3.0 software (GraphPad Software Inc., San Diego, CA, USA) using a Student's $t$-test in combination with Bonferroni correction when more than two groups were compared. $P$-values $<.05$ were considered statistically significant.

\section{Results}

3.1. Induction of Oxidative Stress by GO. Quantification of oxidative stress resulting from the addition of GO to hTECs at different concentrations ( 0 to $100 \mathrm{IU} / \mathrm{mL}$ ) and time points (10 to 240 minutes) shows that incubation of hTECs with GO resulted in a concentration-dependent accumulation of ROS during time (Figure 1).

3.2. Effect of Epoetin Delta on the GO-Induced Oxidative Stress. Preincubation of hTECs with epoetin delta (24 hours before addition of GO; $0-0.1-1-10 \mathrm{IU} / \mathrm{mL}$ ) significantly protects the cells against oxidative stress as indicated by a dose-dependent, attenuated ROS production. Furthermore, it was found that epoetin delta added to the culture medium concomitantly with the induction of oxidative stress attenuated the formation of ROS as well, be it in a less pronounced way. The epoetin delta-induced effects on ROS formation were only observed in 6 out of 9 experiments (hTECs cultures of 9 different kidney specimens) (Figure 2). 


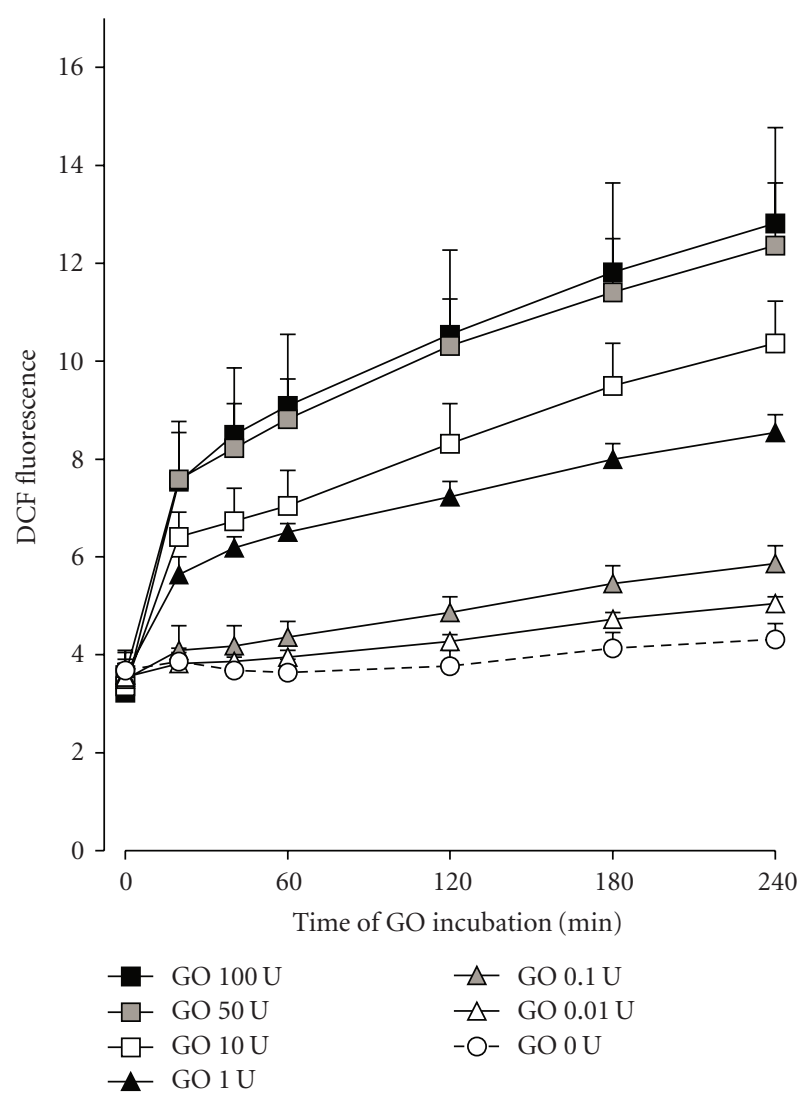

FIgUre 1: Induction of oxidative stress in confluent hTECs by incubation with GO (0 to $100 \mathrm{IU} / \mathrm{mL}$ ) during 0 to 240 minutes. By measuring DCF fluorescence, a concentration-dependent accumulation of ROS was observed during the time.

3.3. Comparison of Epoetin Delta and Epoetin Alfa. Since epoetin delta did not reduce ROS formation in all hTECs cultures, it was investigated whether this was due to either cell culture and/or EPO characteristics. This was done by comparing the effects of epoetin delta to these of epoetin alfa. It became clear that the outcome of these two erythropoiesisstimulating agents (ESA) was similar as both of them either or not protected the same cell cultures from oxidative stress (Figure 3).

3.4. Expression of the Erythropoietin Receptor in Human Tubular Epithelial Cells. As epoetin delta and alfa induced similar effects on oxidative stress in the same culture, the presence or absence of protective mechanisms must be due to culture characteristics. Because EPO exerts its actions via the EPOR, its expression was investigated in two different cultures: one of them showing epoetin deltainduced protection whereas the other did not. In protective as well as nonprotective cultures, EPOR expression was seen in intracellular vesicles (Figure 4). However, only in the culture that showed EPO-induced protection against oxidative stress, EPOR expression could be found at the level of the plasma membrane (Figure 4(a)). Data from additional experiments learned that membranous EPOR expression is only present in highly confluent cultures (data not shown).

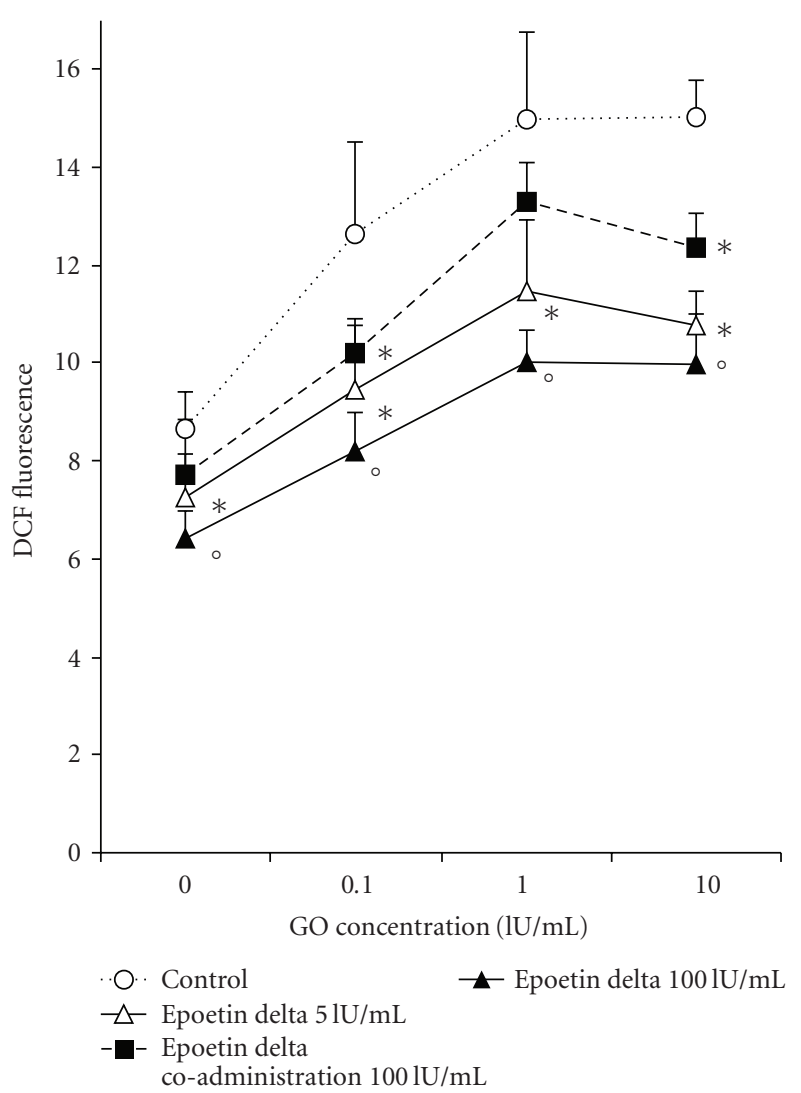

FIgURE 2: GO-induced oxidative stress (240 minutes) in hTECs either pre/coincubated with epoetin delta or not. Epoetin delta attenuated oxidative stress in a dose-dependent way by reducing ROS formation. The data are expressed as the mean \pm SD of 4 monolayers per condition from a single experiment representative of 6 separate experiments. ${ }^{*} P<.05,{ }^{\circ} P<.01$ compared to the control.

3.5. mRNA Expression of Genes Already Known to Be Involved in the Protective Effects of Erythropoietin. In the present study, the mRNA expression of HO-1, AQP-1, and Bcl-2 was assessed in cultures that were either preincubated with epoetin delta before the induction of oxidative stress or not. Under basal conditions (no GO incubation), preconditioning of hTECs with epoetin delta $(100 \mathrm{IU} / \mathrm{mL})$ resulted in a significant upregulation of HO-1 $(1.00 \pm 0.31$ versus 1.56 $\pm 0.37, P<.05)$ and AQP-1 $(1.00 \pm 0.03$ versus 2.26 $\pm 0.12, P<.05)$ mRNA expression. During GO-induced oxidative stress $(1 \mathrm{IU} / \mathrm{mL})$, cultures which were preincubated with epoetin delta $(100 \mathrm{IU} / \mathrm{mL})$ showed a further increase in mRNA expression of all three genes investigated as compared to cultures which were not preincubated with epoetin delta, reaching maximum values 60 minutes after the induction of oxidative stress (HO- $1: 1.07 \pm 0.20$ versus $1.48 \pm 0.19$; AQP$1: 1.61 \pm 0.11$ versus $3.18 \pm 0.22 ; \mathrm{Bcl}-2: 0.97 \pm 0.18$ versus $1.58 \pm 0.40 ; P<.05$ ) (Figure 5). Interestingly, in cultures in which no epoetin delta-protective effect against oxidative stress was seen also no epoetin delta-induced upregulation of the genes under study could be observed (data not shown). 


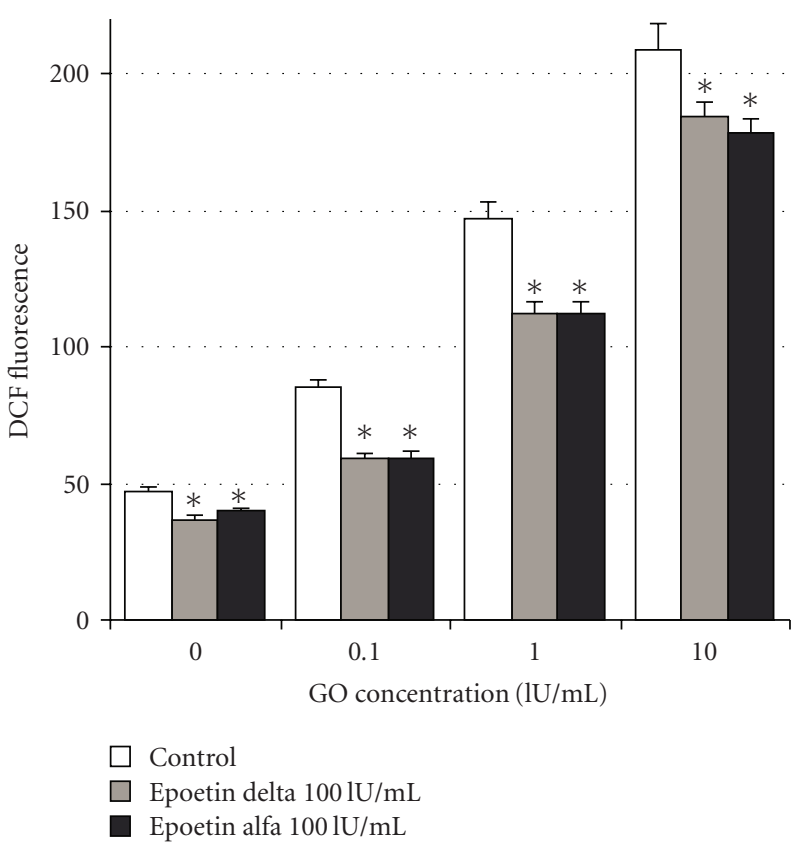

(a) Protection

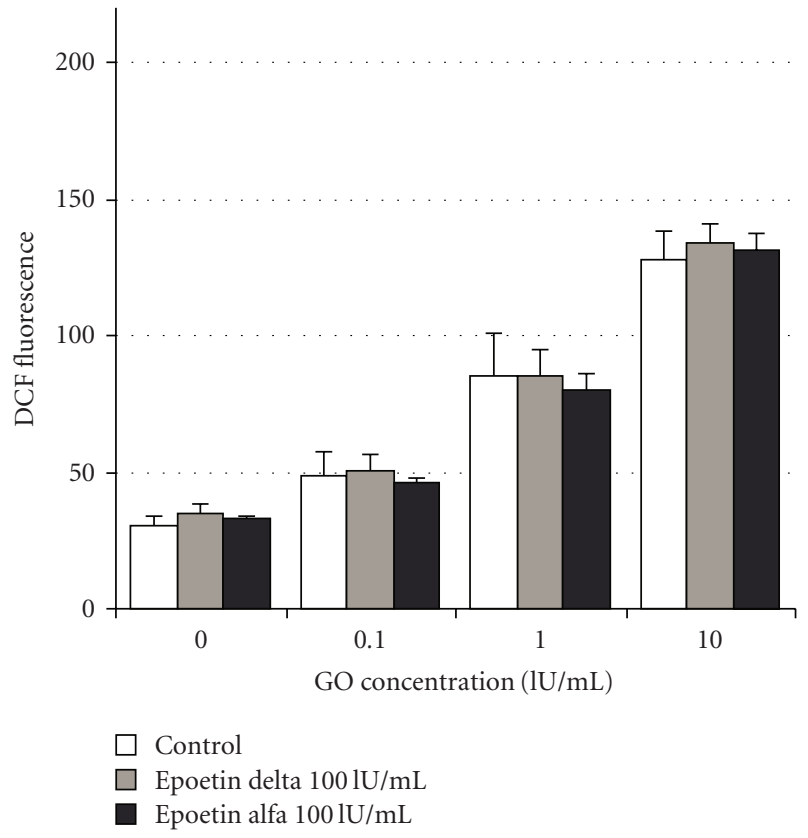

(b) No protection

Figure 3: Comparison of epoetin delta- and epoetin alfa-induced effects on GO-induced oxidative stress (240 minutes) in cell cultures originating from two different kidney specimens, one showing EPO-induced anti-oxidative effects (a) and one where neither epoetin delta nor epoetin alfa had any effect on oxidative stress (b). Both ESA's showed a similar effect on GO-induced oxidative stress: either they were both able to reduce the amount of ROS formed or not. The data are expressed as the mean \pm SD of 4 monolayers per condition from a single experiment representative of 2 separate experiments. ${ }^{*} P<.05$ compared to the control.

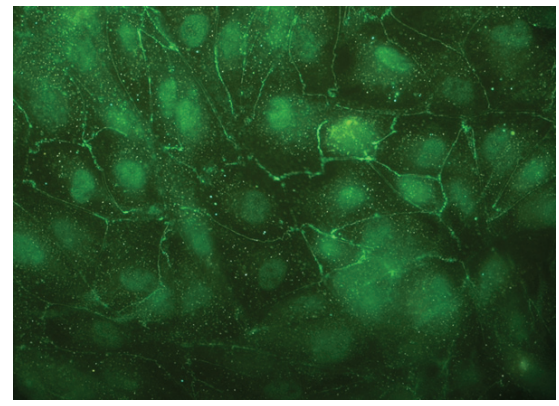

(a)

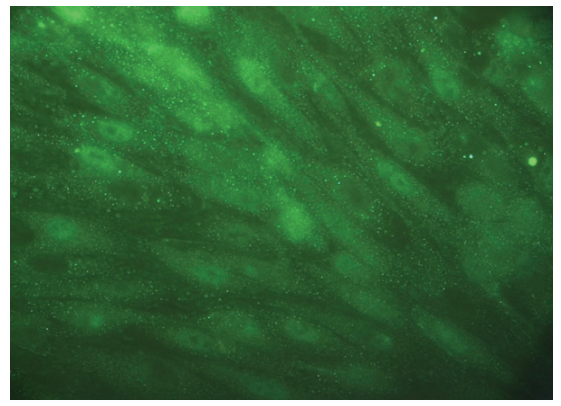

(b)

FIGURE 4: Immunofluorescent staining of EPOR in two cultures of hTECs that show an epoetin delta-induced effect on oxidative stress (a) or not (b). EPOR signal is visualized using the M-20 anti-EPOR antibody and an FITC-labeled (green fluorescence) secondary antibody. Punctate intracellular staining is seen in both cultures while membranous staining is only seen in cultures that showed epoetin delta-induced effects on oxidative stress.

3.6. Effect of Epoetin Delta on the Expression of CPM, DPPIV, and Cygb. Figure 6 shows that preconditioning of hTECs with epoetin delta $(100 \mathrm{IU} / \mathrm{mL})$ resulted in a significant increase of CPM $(1.00 \pm 0.10$ versus $2.09 \pm 0.30, P<.05)$ and DPPIV $(1.00 \pm 0.24$ versus $1.77 \pm 0.56, P<.05)$ mRNA expressions . During GO-induced oxidative stress $(1 \mathrm{IU} / \mathrm{mL})$, cultures which were preincubated with epoetin delta $(100 \mathrm{IU} / \mathrm{mL})$ showed a further increase in mRNA expression of all three genes investigated as compared to cultures which were not preincubated with epoetin delta, reaching maximum values 60 minutes after the induction of oxidative stress (CPM: $1.19 \pm 0.13$ versus $3.56 \pm 0.77$; DPPIV: $1.12 \pm 0.21$ versus $2.61 \pm 0.40$; Cygb: $2.22 \pm 0.37$ versus $3.41 \pm 0.43 ; P<.05)$. Again, this upregulation was only observed in cultures in which epoetin delta exerted a protective effect against oxidative stress; that is, in cultures in which ROS production was suppressed as compared to controls. In cultures in which epoetin delta did not show protective effects, no upregulation of CPM, DPPIV, or Cygb was observed (CPM: $1.00 \pm 0.03$ versus $0.81 \pm 0.13$; DPPIV: $1.00 \pm 0.14$ versus $0.89 \pm 0.14$; Cygb: $1.00 \pm 0.29$ versus 0.87 \pm 0.29 ; NS) (Figure 6). 


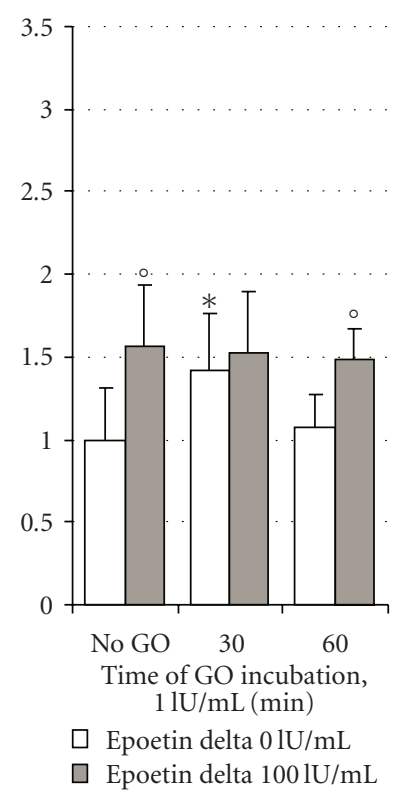

(a) $\mathrm{HO}-1 / \mathrm{GAPDH}$ expression

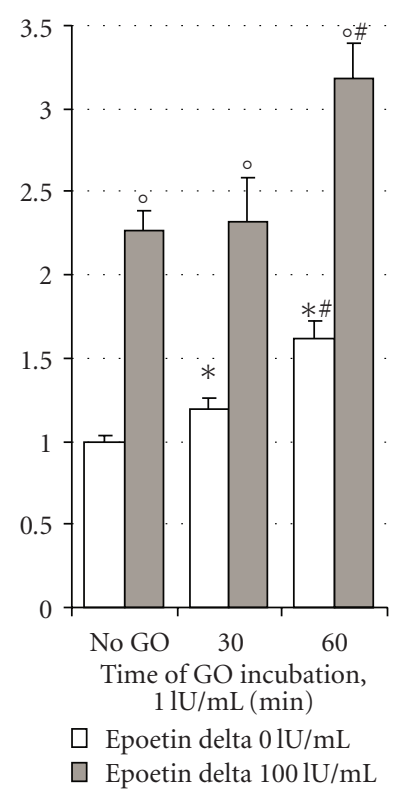

(b) AQP-1/GAPDH expression

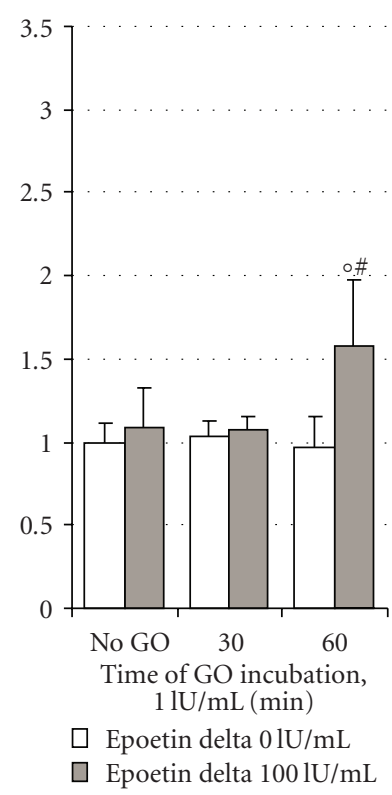

(c) Bcl-2/GAPDH expression

FIGURE 5: Quantitative real-time RT-PCR analysis of HO-1 (a), AQP-1 (b), and Bcl-2 (c) expressions in mixed hTECs under basal conditions and after GO-induced oxidative stress $(1 \mathrm{IU} / \mathrm{mL})$ either or not in the presence of epoetin delta (100 IU/mL). GAPDH was used as endogenous control housekeeping gene. Preconditioning the cells with EPO resulted in a significant upregulation of HO-1 and AQP-1 mRNA. GOinduced oxidative stress further increased HO-1, AQP-1, and Bcl-2 mRNA expressions with maximum levels 60 minutes after induction of oxidative stress. Data are presented as the mean $\pm \mathrm{SD}$ of triplicate determinations of 2 runs (i.e., 6 values each). ${ }^{*} P<.05$ versus no GO, ${ }^{\circ} \mathrm{P}<.05$ versus epoetin delta $0 \mathrm{IU} / \mathrm{mL},{ }^{\#} \mathrm{P}<.05$ versus 30 minutes $\mathrm{GO}$ incubation.

\section{Discussion}

In the present study, oxidative stress was induced using glucose oxidase (GO), an enzyme that, in the presence of glucose, produces $\mathrm{H}_{2} \mathrm{O}_{2}$, the most important source of cellular ROS. We showed that GO indeed induced a concentration-dependent accumulation of ROS in primary hTECs during time. Pretreatment of the primary hTECs with epoetin delta ( 5 or $100 \mathrm{IU} / \mathrm{mL}$ ) resulted in a statistically significant reduction of GO-induced ROS production. As this effect was less pronounced when epoetin delta was administered together with GO, one may assume that EPO (epoetin delta) exerts a direct effect on renal tubular cells by (pre)conditioning these cells towards protection. Interestingly, epoetin delta pretreatment did not protect against oxidative stress in all cultures investigated. In further experiments, we found that epoetin delta and epoetin alfa (a widely used ESA, known to have renoprotective effects both in vivo [11] and in vitro [12]) acted in the same way; that is, both compounds were either protective or not when administered to the same cultures.

In an attempt to explain this intriguing finding, the EPOR expression was investigated in these cell cultures using the M-20 antibody, recently identified as a specific antiEPOR antibody [13]. Since nonerythropoietic properties of EPO most likely are also mediated by EPOR $[14,15]$, its membranous expression is a prerequisite for a culture to be able to respond to EPO. Interestingly, it was observed that in a culture showing a protective EPO-induced response, EPOR staining was present both in intracellular vesicles and at the level of the plasma membrane, while in a nonresponsive culture, the EPOR signal was confined to intracellular vesicles. Further studies showed that membranous EPOR expression is only present in highly confluent cultures. Hence, it was concluded that culture characteristics, more specifically different levels of confluence, going along with the presence and/or absence of membranous EPOR expression, specific characteristics of the kidney donor, as well as the fact that some cell cultures themselves seemed to have better anti-oxidative mechanisms than others ( $c f r$. Figure 3) could contribute to the interesting observation that EPO-mediated anti-oxidative effects are not seen in all cell cultures investigated.

In order to try to identify some specific pathways through which EPO could exert these observed anti-oxidative effects, the EPO-induced effects on HO-1, AQP-1, and Bcl-2 mRNA were investigated. These three genes have already intensively been studied in in vivo experimental setups and in line with previous studies performed in our laboratory [16], preconditioning of hTECs with epoetin delta resulted in a significant upregulation of HO-1 and AQP-1 mRNA expressions.

Induction of HO-1 (or HSP32), known as a protein with antiapoptotic, anti-inflammatory, and cytoprotective properties [17], and its tissue protective effects are frequently seen in several models of renal injury $[18,19]$. EPO-mediated renoprotective effects in vivo as well as in vitro have been partially attributed to the renal upregulation of $\mathrm{HO}-1[16,20]$. One of the mechanisms by which increased HO- 1 expression 


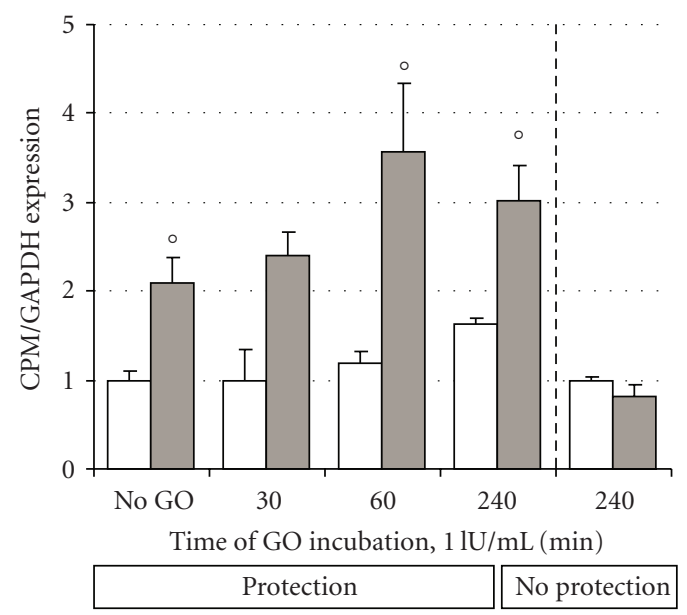

(a)

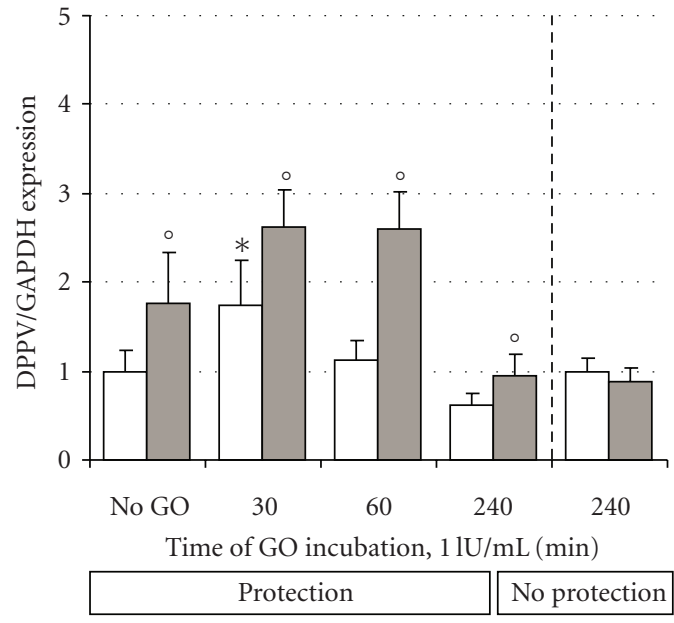

(b)

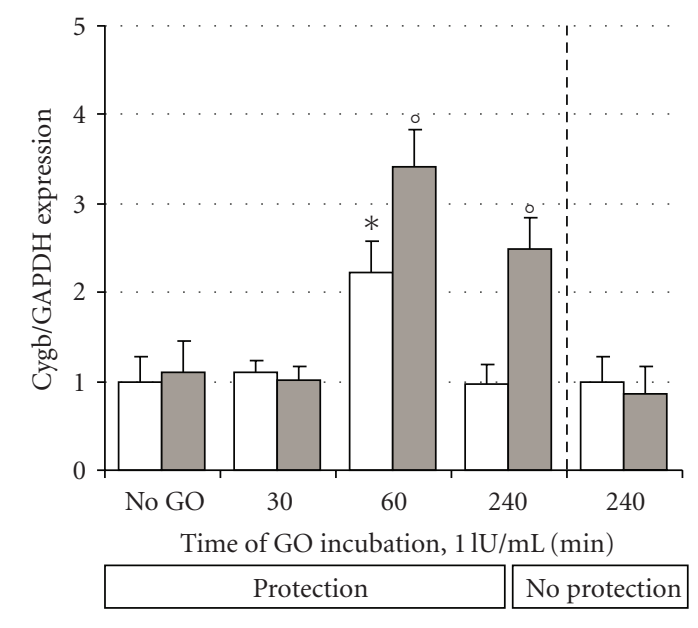

$\square$ Epoetin delta $01 \mathrm{U} / \mathrm{mL}$

$\square$ Epoetin delta $100 \mathrm{lU} / \mathrm{mL}$

(c)

Figure 6: Comparison of the relative (normalized to GAPDH and to calibrator sample) expressions of CPM (a), DPPIV (b), and Cygb (c) under basal conditions and after GO-induced oxidative stress $(1 \mathrm{IU} / \mathrm{mL})$ in cell cultures originating from two different kidney specimens, one showing EPO-induced anti-oxidative effects and one without any effect of EPO on oxidative stress. Preconditioning the cells with EPO resulted in a significant upregulation of CPM and DPPIV, mRNA. GO-induced oxidative stress further increased CPM, DPPIV and Cygb mRNA expressions with maximum levels 60 minutes after induction of oxidative stress. Remarkably, the cell culture in which epoetin delta was not able to induce a protective effect against oxidative stress was also not able to induce upregulation of those mRNA's. Data are presented as the mean $\pm \mathrm{SD}$ of triplicate determinations representative of 2 separate runs (i.e., 6 values each). ${ }^{*} P<.05$ versus no GO, ${ }^{\circ} P<.05$ versus epoetin delta $0 \mathrm{IU} / \mathrm{mL}$.

may contribute to cytoprotection is by catalyzing the degradation of prooxidant heme to the radical scavengers ferritin, biliverdin, and bilirubin [21].

The cytoprotective effects of EPO preconditioning have also been linked to the prevention of renal IRI-induced downregulation of AQP-1 [11], a major transmembranous water channel in cell plasma membranes of the renal proximal tubule and the descending limb of Henle's loop playing a role in urine concentration [22]. We could confirm these results in that we were able to demonstrate a direct (upregulatory) effect of EPO on one of the renal tubular transport proteins present in the kidney. Moreover, our experiments for the first time showed that epoetin delta administration significantly upregulated the AQP-1 expression in primary, GO-treated hTECs, which is in line with the recent observation that AQP- 1 acts as an $\mathrm{O}_{2}$ transporter, thereby facilitating $\mathrm{O}_{2}$ diffusion across the cell membrane [23].

In agreement with the observation that EPO exerts antiapoptotic effects and that $\mathrm{Bcl}-2$ has been reported to be involved in several models of kidney injury [24, 25], Bcl2 mRNA expression was also significantly upregulated in EPO-treated hTECs, under basal conditions as well as after 
GO-induced oxidative stress, hereby pointing to a role for Bcl-2 in the EPO-mediated cell protection against GOinduced oxidative stress.

Interestingly, the epoetin delta-induced upregulation of HO-1, AQP-1, and Bcl-2 expression could only be observed in cell cultures in which the compound induced an attenuation of ROS production again pointing to a direct protective effect on the tubular cells.

As we also aimed to get further insight into the mechanisms underlying EPO-induced antioxidant cytoprotection, expressions of three other genes potentially involved in the protective process were investigated: CPM, DPPIV, and Cygb. Epoetin delta treatment resulted in an upregulation of these genes under basal conditions, which was further increased in cell cultures that showed an epoetin delta-induced protection against GO-induced oxidative stress (and not in cultures that did not show this protection). Although data of the present study do not allow drawing clear-cut conclusions about a role for CPM, DPPIV, and Cygb in the EPO's anti-oxidative properties, the observed EPO-induced alterations in their mRNA expression are worth being considered in view of the already known functions mentioned below.

CPM is a membrane glycoprotein which specifically removes $\mathrm{C}$-terminal basic residues from peptides and proteins $[26,27]$. The wide distribution of CPM in human tissues, including the kidney and the recent finding that CPM would be involved in inflammatory processes [28] prompted us to study the effects of EPO on its expression. Although previous experiments have indicated that CPM is expressed in both the mammalian kidney [27] and in Madin-Darby canine kidney (MDCK) cells [29], we demonstrated for the first time that (i) CPM is expressed in primary cultures of hTECs and (ii) CPM expression is associated with EPOinduced cytoprotection against oxidative stress. Related to these results, literature has mentioned that CPM expression on extravillous trophoblasts is partially regulated by tissue oxygen concentration, and higher oxygen concentrations (20\%) could induce CPM expression [30].

DPPIV is the most intensively studied member of the proline-specific dipeptidyl peptidase (DPP) family. Widely expressed among organs and body fluids and having different substrates in different organs [31], a broad range of potential functions have been attributed to DPPIV. Inhibitors of DPPIV are used in the treatment of dysglycemia [32], limit IRI in the lung [33], and abrogate acute organ rejection in lung and heart transplantation models $[34,35]$. Since DPPIV is expressed on the brush border of PTC [36], by far the most vulnerable cells during ischemic injury, it is of particular interest to investigate potential anti-oxidative effects of EPO on this DPPIV expression in these cells.

Both being cell surface peptidases, CPM and DPPIV have a lot in common and are frequently studied together [37]. In our study, the responses of these two peptidases to GO-induced oxidative stress and EPO-induced protective effects are similar. After EPO administration, these two genes are upregulated concomitantly with EPOR expression at the cell membrane, which might indicate that CPM and DPPIV may be involved in the EPO-mediated anti-oxidative effects.
Cygb, sharing a common ancestry with myoglobin, is a recently discovered member of the vertebrate globin family [38] and is expressed in many different tissues at varying levels $[39,40]$. Evidence has been provided for Cygb to be a hypoxia-induced gene which is transcriptionally upregulated during chronic hypoxia in a hippocampal neuronal cell line [38] and fibroblast cell lineage [41]. More or less in line with the findings of the present study it has been demonstrated that Cygb may reduce the induction of intracellular ROS formation [42]. Xu's study [43] in rat hepatic stellate cells also provides evidence that overexpression of Cygb could protect cells against oxidative stress both in vitro and in vivo. Data of our study for the first time demonstrate that Cygb (i) is expressed in primary hTECs, (ii) is upregulated after EPO administration, and (iii) may play a role in the mechanism(s) underlying EPO-induced anti-oxidative effects. Interestingly, recently we also demonstrated Cygb to be expressed at the protein level in renal tissue (data not shown).

\section{Conclusions}

In the present work, evidence was found for a direct cytoprotective effect of epoetin delta on renal tubular cells. This EPO-induced effect on renal tubular cells may be an important contribution to the EPO-induced renal protective effect seen in vivo. Furthermore, comparison of the localization of the EPOR in EPO-responding versus nonresponding cultures allows to suggest that the cytoprotective effect of epoetin delta in primary hTECs is mediated by the EPOR. Interestingly, the expression of six genes under study was significantly upregulated upon EPO administration in and only in those cell cultures in which an EPO-induced cytoprotective effect was seen, allowing (i) to confirm a role of HO1 , AQP-1, and Bcl-2 in the EPO-induced preconditioning of cells and (ii) to speculate about a role of CPM, DPPIV, and Cygb in this process. Further research with regard to the effects of EPO on the protein expression and function of these proteins is warranted.

\section{Acknowledgments}

This work would not have been possible without the generous cooperation of Dr. Braeckman (University Hospital Brussels), Dr. Verkoelen, and Dr. Asselman (Erasmus Medical Center Rotterdam), Dr. Dekuyper (AZ Maria Middelares, Ghent), and Professor Oosterlinck (University Hospital, Ghent). This work was funded by BOF (Bijzonder Onderzoeksfonds) University of Antwerp and by a research Grant from Shire Pharmaceuticals. Anja Verhulst is a (post) doctoral fellow of the Fund for Scientific Research Flanders (FWO). Xiang-hua Hou is a student of the Shandong University in China and was a fellow of a coculture program between China and Belgium that has been financed by both the China scholarship council and the department of Pathophysiology, University of Antwerp, Belgium. Professor De Meester and Dr. Deiteren (Laboratory of Medical Biochemistry, University of Antwerp) are thanked for their advice concerning the literature dealing with DPPIV 
and CPM. Annelies De Beuf and Xiang-hua Hou equally contributed to this manuscript

\section{References}

[1] G. W. Dryden Jr., I. Deaciuc, G. Arteel, and C. J. McClain, "Clinical implications of oxidative stress and antioxidant therapy," Current Gastroenterology Reports, vol. 7, no. 4, pp. 308-316, 2005.

[2] L. Forsberg, U. de Faire, and R. Morgenstern, "Oxidative stress, human genetic variation, and disease," Archives of Biochemistry and Biophysics, vol. 389, no. 1, pp. 84-93, 2001.

[3] J.-C. Lee, J. Kim, J.-K. Park, G.-H. Chung, and Y.-S. Jang, “The antioxidant, rather than prooxidant, activities of quercetin on normal cells: quercetin protects mouse thymocytes from glucose oxidase-mediated apoptosis," Experimental Cell Research, vol. 291, no. 2, pp. 386-397, 2003.

[4] C. A. Rice-Evans, N. J. Miller, P. G. Bolwell, P. M. Bramley, and J. B. Pridham, "The relative antioxidant activities of plantderived polyphenolic flavonoids," Free Radical Research, vol. 22, no. 4, pp. 375-383, 1995.

[5] P. Katavetin, K. Tungsanga, S. Eiam-Ong, and M. Nangaku, "Antioxidative effects of erythropoietin," Kidney International, no. 107, pp. S10-S15, 2007.

[6] F. H. Bahlmann and D. Fliser, "Erythropoietin and renoprotection," Current Opinion in Nephrology and Hypertension, vol. 18 , no. 1, pp. 15-20, 2009.

[7] M. J. F. Helbert, S. E. H. Dauwe, I. Van der Biest, E. J. Nouwen, and M. E. De Broe, "Immunodissection of the human proximal nephron: flow sorting of S1S2SS3, S1S2 and S3 proximal tubular cells," Kidney International, vol. 52, no. 2, pp. 414-428, 1997.

[8] M. J. F. Helbert, S. E. H. Dauwe, and M. E. De Broe, "Flow cytometric immunodissection of the human distal tubule and cortical collecting duct system," Kidney International, vol. 59, no. 2, pp. 554-564, 2001.

[9] R. E. Gibson-D’Ambrosio, M. Samuel, C. C. Chang, J. E. Trosko, and S. M. D’Ambrosio, "Characteristics of long-term human epithelial cell cultures derived from normal human fetal kidney," In Vitro Cellular \& Developmental Biology, vol. 23, no. 4, pp. 279-287, 1987.

[10] A. Barbouti, P.-T. Doulias, L. Nousis, M. Tenopoulou, and D. Galaris, "DNA damage and apoptosis in hydrogen peroxideexposed Jurkat cells: bolus addition versus continuous generation of $\mathrm{H}_{2} \mathrm{O}_{2}$," Free Radical Biology and Medicine, vol. 33, no. 5, pp. 691-702, 2002.

[11] H. Gong, W. Wang, T.-H. Kwon, et al., "EPO and $\alpha$ MSH prevent ischemia/reperfusion-induced down-regulation of AQPs and sodium transporters in rat kidney," Kidney International, vol. 66, no. 2, pp. 683-695, 2004.

[12] D. A. Vesey, C. Cheung, B. Pat, Z. Endre, G. Gobé, and D. W. Johnson, "Erythropoietin protects against ischaemic acute renal injury," Nephrology Dialysis Transplantation, vol. 19, no. 2, pp. 348-355, 2004.

[13] A. Kirkeby, J. van Beek, J. Nielsen, M. Leist, and L. Helboe, "Functional and immunochemical characterisation of different antibodies against the erythropoietin receptor," Journal of Neuroscience Methods, vol. 164, no. 1, pp. 50-58, 2007.

[14] Y. Li, G. Takemura, H. Okada, et al., "Reduction of inflammatory cytokine expression and oxidative damage by erythropoietin in chronic heart failure," Cardiovascular Research, vol. 71, no. 4, pp. 684-694, 2006.
[15] F. Pajonk, A. Weil, A. Sommer, R. Suwinski, and M. Henke, "The erythropoietin-receptor pathway modulates survival of cancer cells," Oncogene, vol. 23, no. 55, pp. 8987-8991, 2004.

[16] A. De Beuf, A. Verhulst, M. Helbert, et al., "Tubular erythropoietin receptor expression mediates erythropoietin-induced renoprotection," The Open Hematology Journal, vol. 3, pp. 1$10,2009$.

[17] K. A. Kirkby and C. A. Adin, "Products of heme oxygenase and their potential therapeutic applications," American Journal of Physiology, vol. 290, no. 3, pp. F563-F571, 2006.

[18] M. Wagner, P. Cadetg, R. Ruf, L. Mazzucchelli, P. Ferrari, and C. A. Redaelli, "Heme oxygenase-1 attenuates ischemia/reperfusion-induced apoptosis and improves survival in rat renal allografts," Kidney International, vol. 63, no. 4, pp. 1564-1573, 2003.

[19] T. D. Blydt-Hansen, M. Katori, C. Lassman, et al., "Gene transfer-induced local heme oxygenase-1 overexpression protects rat kidney transplants from ischemia/reperfusion injury," Journal of the American Society of Nephrology, vol. 14, no. 3, pp. 745-754, 2003.

[20] P. Katavetin, R. Inagi, T. Miyata, et al., "Erythropoietin induces heme oxygenase-1 expression and attenuates oxidative stress," Biochemical and Biophysical Research Communications, vol. 359, no. 4, pp. 928-934, 2007.

[21] S. W. Ryter and A. M. K. Choi, "Heme oxygenase-1/carbon monoxide: from metabolism to molecular therapy," American Journal of Respiratory Cell and Molecular Biology, vol. 41, no. 3, pp. 251-260, 2009.

[22] S. Nielsen, J. Frøkiaer, D. Marples, T.-H. Kwon, P. Agre, and M. A. Knepper, "Aquaporins in the kidney: from molecules to medicine," Physiological Reviews, vol. 82, no. 1, pp. 205-244, 2002.

[23] M. Echevarría, A. M. Muñoz-Cabello, R. Sánchez-Silva, J. J. Toledo-Aral, and J. López-Barneo, "Development of cytosolic hypoxia and hypoxia-inducible factor stabilization are facilitated by aquaporin-1 expression," Journal of Biological Chemistry, vol. 282, no. 41, pp. 30207-30215, 2007.

[24] E. J. Sharples, N. Patel, P. Brown, et al., "Erythropoietin protects the kidney against the injury and dysfunction caused by ischemia-reperfusion," Journal of the American Society of Nephrology, vol. 15, no. 8, pp. 2115-2124, 2004.

[25] C. W. Yang, C. Li, J. Y. Jung, et al., "Preconditioning with erythropoietin protects against subsequent ischemiareperfusion injury in rat kidney," The FASEB Journal, vol. 17, no. 12, pp. 1754-1755, 2003.

[26] D. Reverter, K. Maskos, F. Tan, R. A. Skidgel, and W. Bode, "Crystal structure of human carboxypeptidase M, a membrane-bound enzyme that regulates peptide hormone activity," Journal of Molecular Biology, vol. 338, no. 2, pp. 257269, 2004.

[27] K. Deiteren, G. Surpateanu, K. Gilany, et al., "The role of the S1 binding site of carboxypeptidase $\mathrm{M}$ in substrate specificity and turn-over," Biochimica et Biophysica Acta, vol. 1774, no. 2, pp. 267-277, 2007.

[28] K. Deiteren, D. Hendriks, S. Scharpé, and A. M. Lambeir, "Carboxypeptidase M: multiple alliances and unknown partners," Clinica Chimica Acta, vol. 399, no. 1-2, pp. 24-39, 2009.

[29] G. B. McGwire, R. P. Becker, and R. A. Skidgel, "Carboxypeptidase M, a glycosylphosphatidylinositol-anchored protein, is localized on both the apical and basolateral domains of polarized Madin-Darby canine kidney cells," Journal of Biological Chemistry, vol. 274, no. 44, pp. 31632-31640, 1999. 
[30] Y. Nishioka, T. Higuchi, Y. Sato, et al., "Human migrating extravillous trophoblasts express a cell surface peptidase, carboxypeptidase-M," Molecular Human Reproduction, vol. 9, no. 12, pp. 799-806, 2003.

[31] A.-M. Lambeir, C. Durinx, S. Scharpé, and I. De Meester, "Dipeptidyl-peptidase IV from bench to bedside: an update on structural properties, functions, and clinical aspects of the enzyme DPP IV," Critical Reviews in Clinical Laboratory Sciences, vol. 40, no. 3, pp. 209-294, 2003.

[32] A.-M. Lambeir, S. Scharpé, and I. De Meester, "DPP4 inhibitors for diabetes-what next?” Biochemical Pharmacology, vol. 76, no. 12, pp. 1637-1643, 2008.

[33] W. Zhai, M. Cardell, I. De Meester, et al., "Intragraft DPP IV inhibition attenuates post-transplant pulmonary ischemia/reperfusion injury after extended ischemia," Journal of Heart and Lung Transplantation, vol. 26, no. 2, pp. 174-180, 2007.

[34] F. J. Jung, L. Yang, I. De Meester, et al., "CD26/dipeptidylpeptidase IV-targeted therapy of acute lung rejection in rats," Journal of Heart and Lung Transplantation, vol. 25, no. 9, pp. 1109-1116, 2006.

[35] A. Belyaev, X. Zhang, K. Augustyns, et al., "Structure-activity relationship of diaryl phosphonate esters as potent irreversible dipeptidyl peptidase IV inhibitors," Journal of Medicinal Chemistry, vol. 42, no. 6, pp. 1041-1052, 1999.

[36] A. J. Kenny, A. G. Booth, and S. G. George, "Dipeptidyl peptidase IV, a kidney brush border serine peptidase," Biochemical Journal, vol. 157, no. 1, pp. 169-182, 1976.

[37] H. Fujiwara, T. Higuchi, Y. Sato, et al., "Regulation of human extravillous trophoblast function by membrane-bound peptidases," Biochimica et Biophysica Acta, vol. 1751, no. 1, pp. 2632, 2005.

[38] E. Fordel, E. Geuens, S. Dewilde, W. De Coen, and L. Moens, "Hypoxia/ischemia and the regulation of neuroglobin and cytoglobin expression," IUBMB Life, vol. 56, no. 11-12, pp. 681-687, 2004.

[39] A. Pesce, M. Bolognesi, A. Bocedi, et al., "Neuroglobin and cytoglobin. Fresh blood for the vertebrate globin family," EMBO Reports, vol. 3, no. 12, pp. 1146-1151, 2002.

[40] A. Shigematsu, Y. Adachi, J. Matsubara, et al., "Analyses of expression of cytoglobin by immunohistochemical studies in human tissues," Hemoglobin, vol. 32, no. 3, pp. 287-296, 2008.

[41] T. Burmester, F. Gerlach, and T. Hankeln, "Regulation and role of neuroglobin and cytoglobin under hypoxia," Advances in Experimental Medicine and Biology, vol. 618, pp. 169-180, 2007.

[42] N. J. Hodges, N. Innocent, S. Dhanda, and M. Graham, "Cellular protection from oxidative DNA damage by over-expression of the novel globin cytoglobin in vitro," Mutagenesis, vol. 23, no. 4, pp. 293-298, 2008.

[43] R. Xu, P. M. Harrison, M. Chen, et al., "Cytoglobin overexpression protects against damage-induced fibrosis," Molecular Therapy, vol. 13, no. 6, pp. 1093-1100, 2006. 


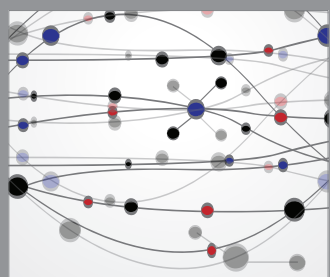

The Scientific World Journal
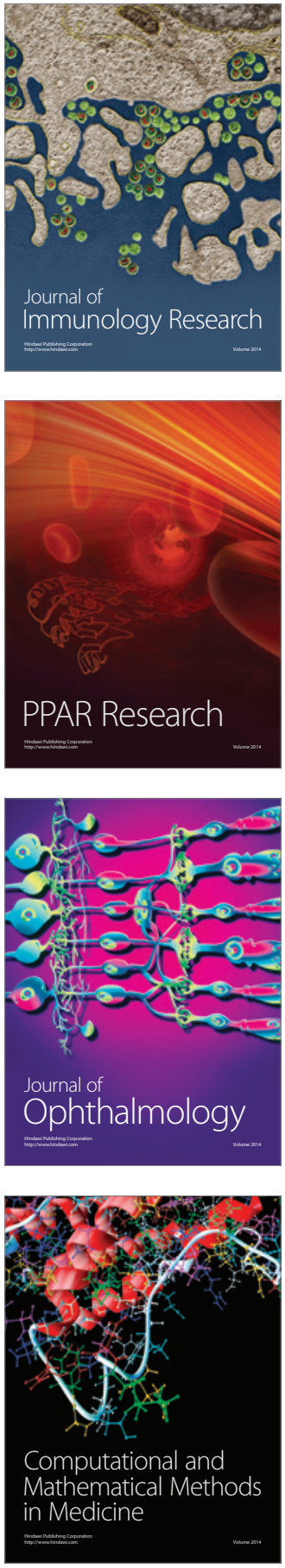

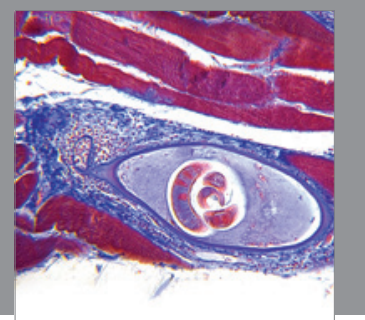

Gastroenterology

Research and Practice
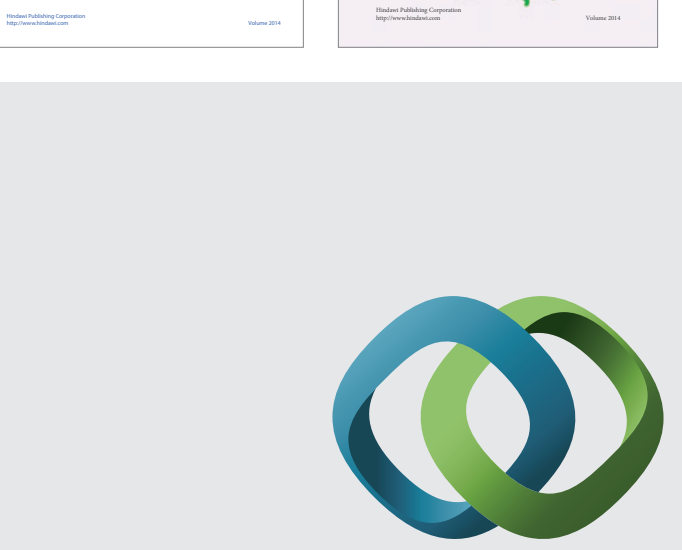

\section{Hindawi}

Submit your manuscripts at

http://www.hindawi.com
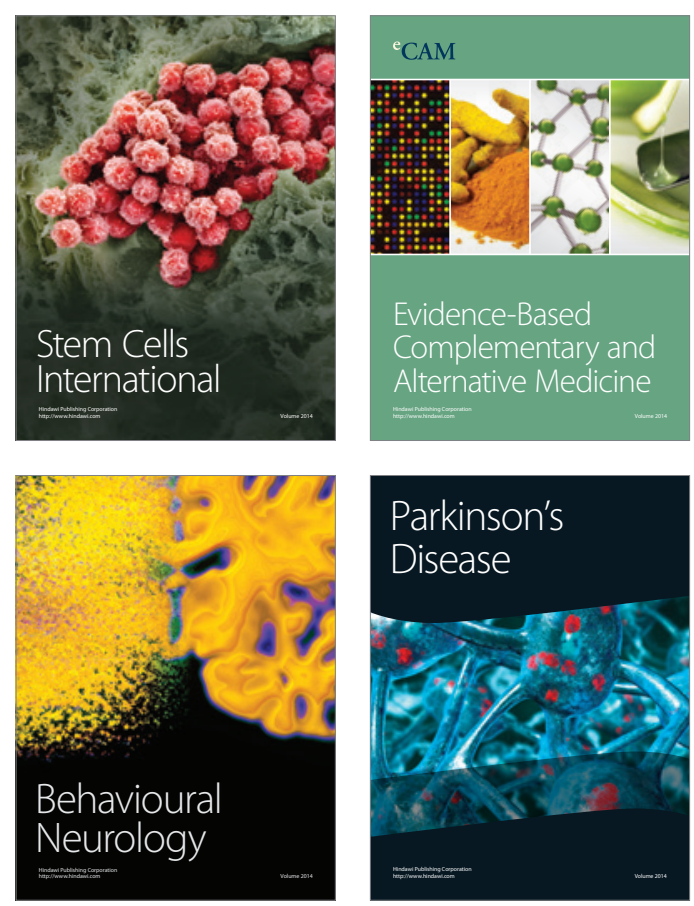

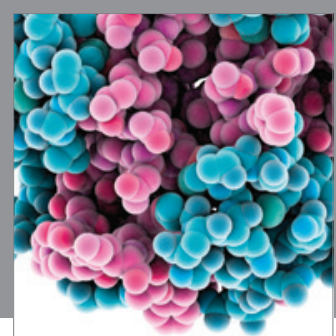

Journal of
Diabetes Research

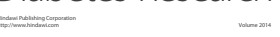

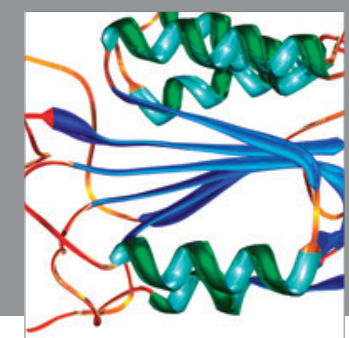

Disease Markers
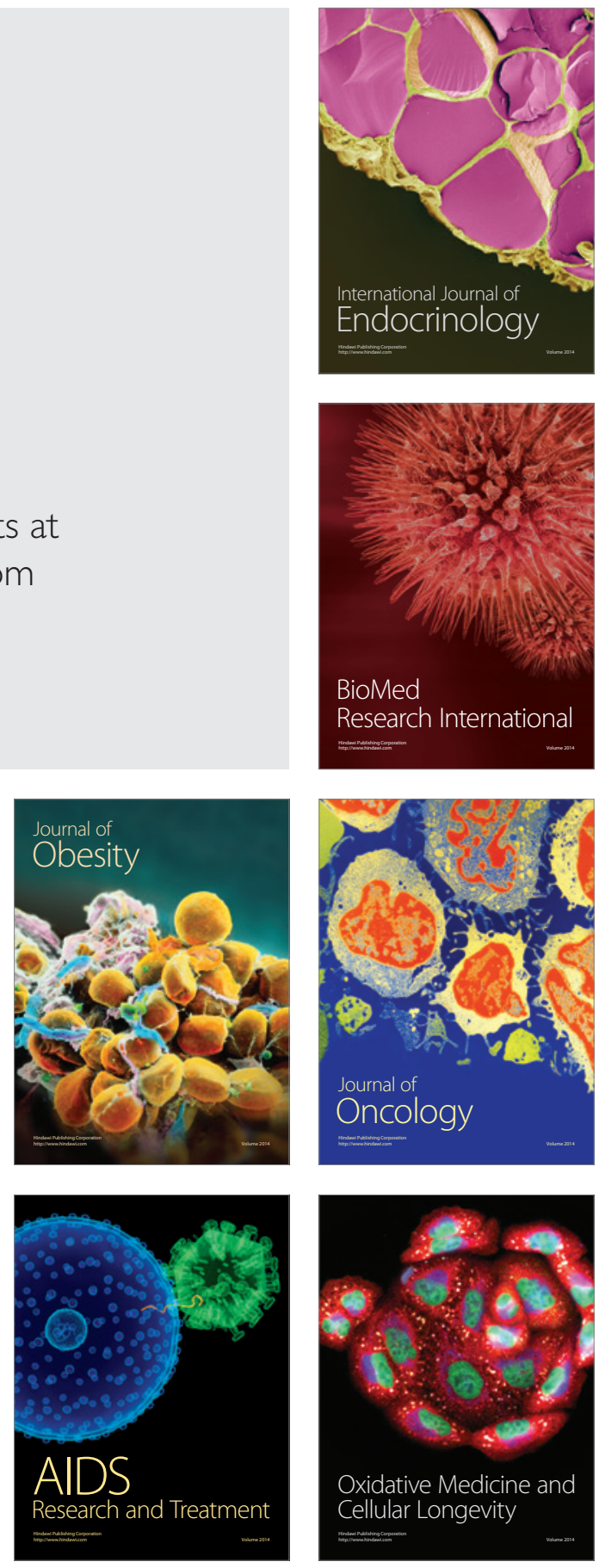